\title{
Pelatihan Masyarakat Lansia Terhadap Peningkatan Keseimbangan Dinamis Dalam Rangka Penurunan Resiko Jatuh
}

\section{Elderly Community Training on Increasing Dynamic Balance in Order to Reduce Fall Risk}

\author{
Tyas Sari Ratna Ningrum ${ }^{1}$, Veni Fatmawati ${ }^{2}$ \\ ${ }^{1}$ Universitas 'Aisyiyah Yogyakarta- Mlangi Nogotirto, Jl. Siliwangi Jl. Ringroad Barat No.63, Area Sawah, \\ Nogotirto, Kec. Gamping, Kabupaten Sleman, Daerah Istimewa Yogyakarta 55592 \\ E-mail: tyasfisio2@gmail.com. No. HP 082227393491
}

Received: 05 Agustus 2021; Revision: 10 September 2021; Accepted: 31 Oktober 2021

\begin{abstract}
Abstrak
Pada lansia, terjadi penurunan anatomis dan fisiologis pada system organ pada tubuhnya. Penurunan fungsi system organ ini menyebabkan terjadinya penurunan keseimbangan dinamis sehingga meningkatkan resiko jatuh. Pada hasil dialog dengan kader di lokasi pengabdian, terdapat penurunan keseimbangan dinamis yang cukup drastic pada lansia di lingkungan tersebut, sehingga lansia mengeluhkan mudah terjatuh saat melakukan aktivitas keseharian. Jika hal ini tidak segera ditanggulangi, maka resiko untuk terjadinya cedera pada lansia akan semakin besar. Tujuan penelitian ini yaitu ingin melakukan pemaparan pada pendahuluan, pengabdian masyarakat kali ini akan memberikan pengetahuan terkait dengan keseimbangan dinamis dan resiko jatuh, setelah itu lansia akan diberikan latihan untuk mengurangi gejala-gejala tersebut. Metode pengabdian ini diawali dengan pemberian pemaparan materi dengan topik "mengenal penuaan dan efeknya terhadap keseimbangan dinamis dan resiko jatuh", setelah itu diberikan pengukuran keseimbangan dinamis untuk mengetahui seberapa besar resiko jatuhnya lalu diberikan pelatihan tentang bagaimana cara meningkatkan keseimbangan dinamis. Pengabdian masyarakat ini meningkatkan pengetahuan masyarakat tentang proses penuaan dan efek terhadap keseimbangan dinamis dan resiko jatuh. Sehingga mengurangi resiko jatuh yang sedang dialami. Pemberian pemaparan materi dan latihan kepada lansia dapat mengingkatkan pengetahuan tentang keseimbangan dinamis dan menurunkan resiko jatuh pada lansia.
\end{abstract}

Kata Kunci Pengetahuan Penuaan; Keseimbangan Dinamis; Resiko Jatuh

In the elderly, there is an anatomical and physiological decline in the organ systems in the body. Decreased function of this organ system causes a decrease in dynamic balance, increasing the risk of falling. In the results of the dialogue with the cadres at the service location, there was a drastic decrease in dynamic balance in the elderly in the environment, so that the elderly complained of falling easily when carrying out daily activities. If this is not addressed immediately, the risk for injury to the elderly will be even greater. The purpose of this study is to explain in the introduction, this community service will provide knowledge related to dynamic balance and the risk of falling, after which the elderly will be given exercises to reduce these symptoms. This service method begins with giving material exposure with the topic "knowing aging and its effects on dynamic balance and the risk of falling", after which measurements of dynamic balance are given to find out how big the risk of falling is and then given training on how to improve dynamic balance. This community service increases people's knowledge about the aging process and its effects on dynamic balance and the risk of falls. Thus reducing the risk of falling that is being experienced. Providing material and exercise exposure to the elderly can increase knowledge about dynamic balance and reduce the risk of falling in the elderly.

Keyword : Knowledge Of Aging; Dynamic Balance; Risk Of Falling

Ratna Ningrum, T., \& Fatmawati, V. (2021). Pelatihan Masyarakat Lansia Terhadap Peningkatan Keseimbangan Dinamis Dalam Rangka Penurunan Resiko Jatuh. Masyarakat Berdaya dan Inovasi, 2(2), 112 - 117. doi:https://doi.org/10.33292/mayadani.v2i2.70 


\section{PENDAHULUAN}

Di masa mendatang, jumlah lansia di Indonesia semakin bertambah. Tahun 1990 jumlah lansia 6,3\% (11,3 juta orang), pada tahun 2015 jumlah lansia diperkirakan mencapai 24,5 juta orang dan akan melewati jumlah balita yang pada tahun 2015 diperkirakan mencapai 18,8 juta orang (Pudjiastuti \& Utomo, 2002). Lansia bukan suatu penyakit, namun merupakan tahap lanjut dari suatu proses kehidupan yang ditandai dengan penurunan kemampua tubuh untuk beradaptasi dengan stress lingkungan (Padila, 2013). Penurunan kemampuan berbagai organ, fungsi dan system tubuh itu bersifat alamiah. Pada umumnya tanda proses menua mulai tampak sejak usia sekitar 60 tahun (Erfandi, 2009).

Pelayanan kesehatan termasuk Fisioterapis dalam hal ini sangat diperlukan karena lansia sangat rentan terhadap penyakit dan cidera. Peran fisioterapi dalam hal ini meliputi aspek; peningkatan (promotive), pencegahan (preventive), pengobatan (curative), pemulihan (rehabilitative) dan pemeliharaan (maintenance). (Erdiana Sari, 2016).

Melihat keragaman masalah kesehatan pada lansia, upaya pencegahan harus diutamakan. Masalah kesehatan lansia tidak terjadi seketika itu saja, tetapi melalui proses kemunduran yang panjang (Sari, 2013). Proses itu dapat dihambat atau dalam beberapa hal dapat dicegah apabila upaya pencegahan dilakukan sejak dini, terpadu, terus menerus dan berkesinambungan (Ashofi \& Hartanti, 2016).

Proses penuaan adalah siklus kehidupan yang ditandai dengan tahap-tahap menurunnya berbagai fungsi organ tubuh, misalnya sistem kardiovaskuer, pernafasan, pencernaan maupun fungsi kognitifnya. Proses penuaan disebut juga senencene yang artinya tumbuh menjadi tua. Terkait dengan perubahan yang terjai pada system tubuhnya, lansia memiliki probematika yang sangat perlu diperhatikan. Karena mereka memiliki suatu keadaan yang memicu munculnya gejala mudah jatuh

1. Jatuh merupakan suatu kejadian yang dilaporkan penderita atau saksi mata yang melihat kejadian, yang mengakibatkan seseorang mendadak terbaring/terduduk di lantai atau tempat yang lebih rendah dengan atau tanpa kehilangan kesadaran atau luka (Akhmadi, 2008).

2. Jatuh dipengaruhi oleh berbagai faktor, diantaranya faktor intrinsik (gangguan gaya berjalan, kelemahan otot ekstremitas bawah, kekuatan sendi dan sinkope-dizziness), dan faktor ekstrinsik (lantai yang licin dan tidak rata, tersandung oleh benda-benda, penglihatan kurang karena cahaya yang kurang terang) (Kuncoro, 2010).

Gejala ini perlu memperoleh penanganan segera. Jika tidak, resiko cedera akan sangat tinggi. Penanganan terhadap resiko cedera dapat dilakukan dengan peningkatan keseimbangan dinamis. Dan pelatihan lansia terhadap keseimbangan dinamis dapat menurunkan resiko jatuh (Notoadmodjo, 2010). Keseimbangan dinamis dapat dicapai dengan pelatihan yang dilakuakn secara teratur dan benar. Oleh karena itu, di samping memberikan pemaparan materi terhadap lansia dan kader, akan diberikan juga pelatihan untuk meningkatkan keseimbangan dinamis (Fadli, 2015). 


\section{METODE}

Dengan mengadakan pemaparan materi dan pembentukan kelompok diharapkan dapat memberikan informasi kepada lansia tentang keseimbangan dinamis dan resiko jatuh. Kegiatan yang dilakukan dalam kegiatan ini adalah:

1. Dengan melibatkan mahasiswa S1 Fisioterapi, Tim pengusul program akan melakukan pendekatan kepada pihak-pihak terkait tentang keinginan Tim untuk melakukan kerjasama dengan pengurus posyandu lansia di desa tersebut sekaligus sebagai desa binaan.

2. Tim dengan dibantu oleh mahasiswa S1 Fisioterapi akan melakukan

Koordianasi lanjutan kepada pihak-pihak terkait untuk membantu mensosialisasikan kepada lansia yang ada diwilayahnya.

3. Tim dengan dibantu oleh mahasiswa S1 Fisioterapi akan melakukan Pelatihan kader sehingga nantinya kader bisa membimbing lansia.

Kegiatan ini akan diberikan sebanyak 1 kali dalam 1 bulan selama 4 bulan berturut-turut dengan alokasi waktu 300 menit setiap pertemuan.

\section{Partisipasi Mitra}

Selama pengabdian ini berlangsung, Mitra berperan aktif dalam semua kegiatan yang sudah dirancang oleh tim pengusul program pengabdian ini. Dalam hal ini, bentuk partisipasi Mitra adalah menyediakan fasilitas berupa ruangan yang bisa dipakai untuk kegiatan-kegiatan program pengabdian. Selain itu, Mitra juga berperan aktif dalam membantu pengusul untuk menginformasikan kepada lansia tentang kegiatan pengabdian ini dan membantu mengkondisikan lansia selama kegiatan berlangsung.

\section{HASIL DAN PEMBAHASAN}

\section{Gambaran Lokasi dan Target PKM}

Lokasi pelaksanaan pengabdian masyarakat ini dilakukan di Posyandu lansia As Syifa, yang berada di Dusun Sawahan I Rt 06 Rw 30 Nogotirto Gamping Sleman Yogyakarta. Di Posyandu Lansia As Syifa, terdapat 60 lansia yang aktif dalam sekali sebulan melakukan program pemeriksaan rutin dari Puskesmas. Dari data yang di dapatkan oleh pelaksana, yang berada di Kecamatan Gamping, Kabupaten Sleman.

\section{Pelaksanaan dan Hasil Kegiatan PKM}

Dalam praktiknya, tim dibantu oleh kader posyandu melakukan pendataan terhadap warga lansia yang masih aktif. Dari 60 lansia yang aktif dalam kegiatan, dalam pelaksanaan pengabdian masyarakat hadir 57 orang yang terdiri atas lansia laki-laki dan perempuan. Pelaksanaan pengabdian masyarakat ini dilakukan pada hari jumat dan sabtu, 25-26 Oktober 2019 dari pukul 15.00-16.30 yang terletak di rumah salah satu warga. Pelaksanaan awal dimulai dengan pemaparan pentingnya menjaga keseimbangan melalui penjelasan di leaflet. 
Pada penjelasan di leaflet, pelaksana menjelaskan bahwa keseimbangan dinamis sangat penting untuk dijaga demi menjaga agar resiko jatuh tidak menimbulkan cedera yang akan mempersulit aktivitas keseharian lansia. Dari hasil interaksi dengan lansia, diperoleh hasil bahwa dari pengalaman lansia, beberapa memiliki riwayat jatuh yang menyebabkan nyeri pinggang atau bahkan nyeri lutut.

Dari data yang diperoleh pelaksana, dari 57 orang yang hadir, 11 diantaranya pernah mengalami jatuh dalam 1 bulan terakhir. 5 di antaranya harus menjalani pengobatan karena nyeri yang berlebih terutama di area pinggang saat aktivitas. Akhirnya, lansia memerlukan korset saat melakukan aktivitas sehari-hari. Saat melaksanakan pertemuan lansiapun beliau menggunakan korset. Dari beberapa contoh nyata, yang ada di sekitar lansia, dapat disimpulkan bahwa menjaga keseimbangan dinamis sangatlah penting. Pelaksana memberikan edukasi untuk latihan yang mudah untuk dilakukan oleh lansia bahkan di rumah. Latihan yang dicontohkan oleh pelaksana di antaranya:

\section{a. Latihan core stability.}

Latihan ini selain untuk menjaga keseimbangan kinerja otot bagian punggung dan perut sehingga makin memprkuat COG sehingga meningkatkan keseimbangan dinamis sehingga dapat mengurangi resiko jatuh (Dika, 2019). Core stability exercise adalah kemampuan untuk mengontrol posisi dan gerak dari trunk sampai pelvic yang digunakan untuk melakukan gerakan secara optimal, perpindahan, kontrol tekanan dan gerakan saat aktifitas. Kerja core stability memberikan suatu pola adanya stabilitas proksimal yang digunakan untuk mobilitas pada distal. Pola proksimal ke distal merupakan gerakan berkesinambungan yang melindungi sendi pada distal yang digunakan untuk mobilisasi saat bergerak. Saat bergerak otot-otot core meliputi trunk dan pelvic, sehingga membantu dalam aktifitas, disertai perpindahan energi dari bagian tubuh yang besar hingga kecil selama aktifitas

\section{b. Latihan Jalan tandem}

Latihan yang dilakukan dengan cara berjalan dalam satu garis lurus dalam posisi tumit kaki menyentuh jari kaki yang lainnya sejauh 3-6 meter, latihan ini dapat meningkatkan keseimbangan postural bagian lateral, yang berperan dalam mengurangi resiko jatuh pada lansia (L. Chang et al, 2008). Latihan Jalan Tandem memakai teknik yang membangkitkan aktivasi otot pronator dan supinator kaki (melatih koordinasi, proprioseptif dan otot stabilisator pergelangan kaki). Aktivasi kontraksi ini diupayakan terjadi secara semi otomatis, karena sejatinya aktivitas stabilisasi merupakan sistem yang berlangsung pada Central Pattern Generator (CPG). Pada perkembangan manusia fungsi CPG yang benar menjadi bergantung pada integrasi saraf yang lebih tinggi, yaitu pada sistem saraf pusat, pada cotex cerebral. Aktivasi otot sekuensi temporal melibatkan CPG spinal dan integrasi sirkuit neural dengan intput pusat otak yang lebih tinggi. Untuk mencapai gerakan semi otomatis yang dimaksud, maka latihan proprioseptif juga melibatkan gerakan yang lambat dalam setiap perpindahan gerak dan posisi, untuk memberikan kesempatan pada nuclei subcortical dan basal ganglia untuk menganalisa sensasi posisi dan mengirimkan umpan balik berupa kontraksi otot yang diharapkan. Latihan inilah yang kemudian akan diadaptasi pada CPG sebagai stabilitas 
fungsional yang baru. Latihan proprioseptif ini, bermanfaat meningkatkan keseimbangan pada lansia dikarenakan menurunnya fungsi motorik pada sistem saraf pusat, sehingga dengan aktivasi motorik tersebut meningkatkan respon proprioseptif yang dapat meningkatkan stabilitas sendi dan meningkatkan keseimbangan pada lansia (Nugrahani Pn, 2014).

Dalam pelaksanaan pengabdian masyarakat ini, lansia sangat bersemangat untuk melakukan semua latihannya. Dan pelaksana memastikan bahwa lansia dapat melakukan gerakannya dengan baik sehingga nantinya memperoleh hasil yang maksimal. Pelaksanaan dilakukan dalam 2 hari, hari pertama pembukaan dan penyuluhan, hari kedua dilaksanakan edukasi dengan mereview penyuluhan di hari pertama dan ditambah pemberian edukasi dan penutup.

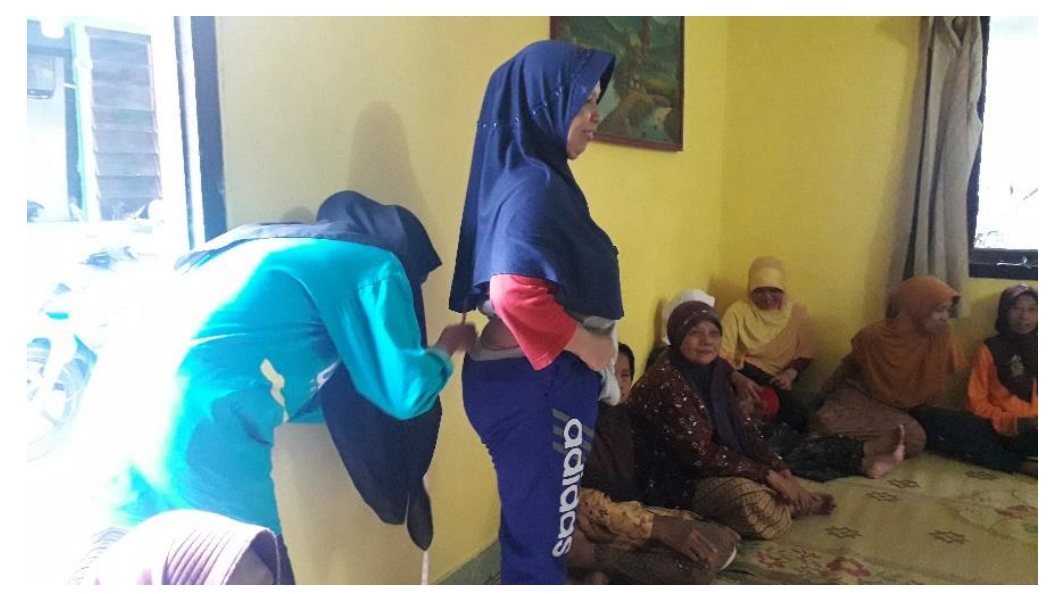

Gambar 1. Pemberian Pengukuran dan Penyuluhan masyarakat desa Sawahan

\section{SIMPULAN}

Kesimpulan dari pengabdian masyarakat ini adalah pentingnya pengetahuan tentang keseimbangan dinamis dan resiko jatuh terhadap keadaan lansia. Saran yang diberikan pelaksana kepada semua lansia untu dapat selalu melaksanakan kegiatan pertemuan posyandu lansia dengan rutin agar dapat menambah pengetahuan dan memeroleh pemeriksaan dari tenaga kesehatan. Selain itu, untuk dapat secara rutin melaksanakan latihan yang telah diberikan dan mengaplikasikan pengetahuan tentang resiko jatuh.

\section{UCAPAN TERIMA KASIH}

Penulis mengucapkan terimakasih sebesar-besarnya kepada Universitas Aisyiyah yogyakarta dan LPPM universits Aisyiyah Yogyakarta yang telah memfasilitasi dan memberikan dana dalam kegiatan pengabdian masyarakat ini dan juga tidak lupa saya ucapkan terimakasih kepada mahasiswa yang telah membantu jalannya pengabdian masyarakat ini, kader posyandu lansia yang telah membantu dan memfasilitasi tempat pelaksanaan pengabdian masyarakat serta seluruh lansia yang menghadiri kegiatan ini dengan semangat. 


\section{DAFTAR PUSTAKA}

Akhmadi. (2008). Menjaga Kesehatan Lanjut Usia Agar Tetap Prima.

Ashofi, F., \& Hartanti, R. D. (2016). Hubungan Dukungan Keluarga Terhadap Tingkat Kemandirian Pasien Stroke Di Wilayah Kerja Puskesmas Wonopringgo Kabupaten Pekalongan.

Dika, M. (2019). Perbedaan Pengaruh Ankle Strategy Exercise Dan Jalan Tandem Untuk Meningkatkan Keseimbangan Dinamis Lansia Di Posyandu Ediyuswo Wiratama V Yogyakarta.

Erdiana Sari, Y. (2016). No Title.

Erfandi. (2009). Pengetahuan Dan Faktor-Faktor Yang Mempengaruhi. http://forbetterhealth.wordpress.com/2009/04/19/ pengetahuan-dan-faktor-faktor-yangmempengaruhi.

Fadli, F. (2015). Faktor-Faktor Yang Mempengruhi Minat Lansia Dalam Mengikuti Posyandu Lansia Buko Kabupaten Bolaang Mongondow Utara.

Kuncoro. (2010). Dukungan social pada lansia.

L. Chang et al. (2008). An 8T-SRAM for Variability Tolerance and Low-Voltage Operation in HighPerformance Caches. Journal of Solid-State Circuits, 43(4, p.), 956-963. https://doi.org/doi: 10.1109/JSSC.2007.917509.

Notoadmodjo. (2010). Pendidikan dan Perilaku Kesehatan. Rineka Karya.

Nugrahani Pn. (2014). Latihan Jalan Tandem Lebih Baik Daripada Latihan Dengan Menggunakan Swiss Ball Terhadap Peningkatan Keseimbangan Untuk Mengurangi Resiko Jatuh Pada Lanjut Usia (Lansia). Jurnal Fisioterapi., 14(Nomor 2).

Padila. (2013). Asuhan Keperawatan Penyakit Dalam. Nuha Medika.

Pudjiastuti, S. S., \& Utomo, B. (2002). Fisioterapi Pada lansia (1st ed.). Buku Kedokteran EGC.

Sari, C. (2013). Sari, C. (2013). Kemandirian pada Lansia. Jakarta. 